\title{
Measurement of temporary prop loads at Mayfair car park
}

\section{J. Richards, G. Holmes and D. R. Beadman}

\section{S. P. Marchard}

A most interesting paper expanding our knowledge on this subject. Perhaps I can add a little from my experience of ascertaining strut temperatures, which is even more difficult than it appears in the paper. The surface temperature of the steel exposed to direct sunlight varies rapidly in the event of clouds passing across the sun. The temperature gradient between sun and shade occurs over approximately $50 \mathrm{~mm}$, and where the temperatures were measured on the topside and underside of the top flange of an I section, the underside was at shade temperature. It would be useful to know the temperatures on the inside of a tubular section. It is possible that we may in fact be overestimating the average temperature rise.

Could the authors advise us of the type of analysis and soil parameters used to arrive at the design loads, and of the cost of the monitoring operation (including or excluding staff time in analysing the results).

\section{INDEX OFADVERTISERS}

Keller Ground Engineering

Ashdown Site Investigation Ltd

Scott Wilson

Rock \& Alluvium Ltd

STATS Ground Engineering Division

G-TEC

Keller Grand Engineering

ABG Geosynthetics Ltd

Geotechnical Developments Ltd

Bachy Soletanche

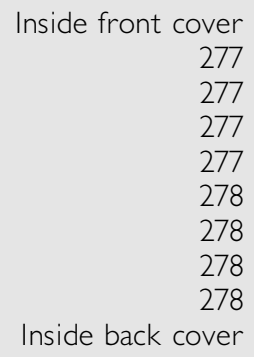

Inside front cover 